\title{
Economic Modelling for Water Quantity and Quality Management: A Welfare Program Approach
}

\author{
Xueqin Zhu • Ekko C. van Ierland
}

Received: 18 December 2010 / Accepted: 20 March 2012 /

Published online: 3 April 2012

C The Author(s) 2012. This article is published with open access at Springerlink.com

\begin{abstract}
This paper presents an integrated economic model which is able to explicitly address both water quantity and quality. We use a welfare program to maximize social welfare subject to the economic and ecological constraints, where interactions, emissions and environmental impacts are incorporated. Such a welfare program can provide the marginal values of commodities and therefore can price water by means of shadow pricing. The optimal solution to a specified program provides the optimal response strategies, i.e. the efficient allocation of resources in the economy including water use and the efficient level of water quality. We illustrate the mechanism in a numerical example and show, as an example, how we can achieve efficiency by reserving water in the high season for times of high demand in the low season and by introducing price differentiation between the two seasons.
\end{abstract}

Keywords Water management - Economic models - Welfare program - Water pricing · Water reservation · Efficiency

\section{Introduction}

The world is facing serious water shortages and millions in the world are suffering from water pollution with large health risk, particularly for the poor and for children (Shaw 2005). In the future these problems will be aggravated by population growth, more economic activity and increasing demand for water. The problems will become even more serious due to global change, including deterioration of ecosystems and climatic change.

To solve these water problems, different options have been identified. Among all, Integrated Water Resources Management (IWRM) proposed by the Technical Advisory Committee of Global Water Partnership has become the most cited option, which promotes the co-ordinated development and management of water, land and related resources in order

X. Zhu $(\bowtie) \cdot$ E. C. van Ierland

Environmental Economics and Natural Resources Group, Wageningen University, Hollandseweg 1, 6706

KN Wageningen, The Netherlands

e-mail: xueqin.zhu@wur.nl 
to maximize the resultant economic and social welfare in an equitable manner without compromising the sustainability of vital ecosystems (GWP-TAC 2000).

Integrated resources management implies that we should consider the complexity of humanenvironment systems and understand the feedback effects, non-linearities, time delays and changes in human behaviour as a consequence of policy interventions (Pahl-Wostl 2004). Integrated water management, which aims to maximize economic and social welfare, aims at optimality or efficiency. However, efficient allocation requires clear insight in water use rights and proper pricing of water (Dinar and Letey 1991). The amount of water allocated to meet basic human and environmental needs depends on biological, ecological but also socio-political considerations (Kemper 1996; Olmstead 2010). Water issues can no longer be separated from energy, food and environmental issues (Hellegers et al. 2008). Hence, we need to understand the functioning of the water system and the economic context in which water is used. This would enable us to identify solutions that keep rivers flowing, and prevent deterioration of flora and fauna, i.e. to assure the functioning and productivity of aquatic and terrestrial ecosystems.

Economic models can support water policies aiming at sustainable allocation and quality conservation of water (see e.g. Braden and van Ierland 1999; Olmstead 2010). Europe's Water Framework Directive (WFD) recommends applying economic methods to support the identification of measures to achieve the environmental objectives. It calls for a wider consideration of economic instruments (e.g. water pricing, charges and taxes) to provide adequate incentives for reducing pressures exerted on water resources. In the literature of economic analysis of water, there are at least four strands of economic models or methods: i) game theoretical models (e.g. Loehman and Dinar 1994; Ansink and Ruijs 2008); ii) valuation methods (Viscusi et al. 2008); iii) optimization models (e.g. Yaron 1979; Chakravorty et al. 1995; Babel et al. 2005; Qureshi et al. 2008; Fisher 2008); and iv) integrated hydro-economic models (Rosegrant et al. 2000; Cai et al. 2003; Heinz et al. 2007; Koch and Grünewald 2009; Prodanovic and Simonovic 2010). These models deal with water issues from different perspectives. Game theoretical approaches are mainly used for establishing inter-regional or international water allocation agreements. Valuation methods are usually used in cost-benefit analysis of water projects. Optimization models maximize total benefits from water and thus allocate the available water efficiently. Particularly, hydro-economic models represent spatially distributed water resource systems, infrastructure, management options and economic values in an integrated manner (Harou et al. 2009). They integrate the economic processes with the hydrological processes and maximise the economic benefit from water supply and hydroelectricity generation to examine some specific "what-if" scenarios. They are becoming more and more important in water management.

However, important feedback effects from the water system to the economy and from the economy to the water system are often missing in existing economic models (Brouwer and Hofkes 2008). Batten (2007) identified the following challenges for economists. First, environmental costs and other externalities must be incorporated into water pricing regimes. Second, we must develop ecological sustainable water trading regimes that facilitate efficient allocation of water for all uses (including ecosystem services). Third, we must address the issue of qualitative changes in the long run. New tools and approaches are therefore needed.

The economic literature provides only few examples of well-integrated water management models. For example, Keyzer (2000) developed a theoretical model framework which adapts capital theory to value the stocks and flows of water with specific consideration of the water regeneration process and its sustainable use in a river basin system. The model is written in a welfare program with the characteristics of an economic general equilibrium and deals with water quantity issues. It is applied to the Upper-Zambezi river (Albersen et al. 2003). However, water quality issues are not explicitly considered. 
Our objective in this paper is to develop an integrated economic model which is able to address both water quantity and quality explicitly. Particularly, we capture the interactions between the economic and the water system considering the feedback effects, the economic functions of water as inputs and amenity services, and the environmental services in a welfare program. This allows us to explicitly consider water quantity and quality in a general equilibrium setting. The objective function of the welfare program is to maximize the social welfare subject to the economic and water quantity and quality constraints. Solving the welfare program leads to the most efficient allocation of water quantity and the efficient level of water quality as well as optimal water prices. ${ }^{1}$ We contribute to the literature on integrated water management by presenting a model framework that consistently and simultaneously deals with quantity allocation and water quality, through pricing water by Lagrange multipliers (i.e. shadow pricing) and by determining compensation rules for relevant externalities.

The organization of the paper is as follows. Section 2 discusses the economic functions of water and their special features (e.g. rivalry/non-rivalry and excludability/non-excludability). This prepares us to address the economic mechanisms of dealing with water use efficiency and water quality in different situations. Section 3 explores the economic mechanisms of managing water quantity as a rivalrous good (e.g. a private good, or a common-pool resource) and water quality as a non-rivalrous good (e.g. a public good). Section 3 also elaborates on the economic instruments of dealing with water quality issues, including how pollution compensation or a tax should be determined. Section 4 illustrates how to work with the model framework in an example, including the model specification and how to solve the program. It also discusses policy implications. Section 5 concludes.

\section{Special Features of Water}

\subsection{Water as an Economic Good and a Natural Resource}

Water is part of the environmental resource systems. There are two primary types of fresh water in the natural environment: surface water consisting of rivers, lakes and oceans and underground water beneath the earth's surface in soils or rocks. In literature, the functions of water are classified in different ways (see e.g. Briscoe 2005; Young 2005). Briscoe (2005) classified five types of values of water: irrigation for agriculture, hydropower generation, household purposes, industrial purposes and environmental purposes. Obviously, the first four values are directly related to the economic activities and therefore can be treated as direct input to economic system, while the last (environmental purposes) is related to the maintenance of wetlands, wildlife support and river flows and therefore can be treated as the environmental services function. Water provides environmental services including support of, and habitat for aquatic life, animals and plants in riparian areas, and birds that feed on aquatic life. Humans sometimes just enjoy simply looking at, or being near, a water body. These activities are referred to as water's service flows to humans (due to the amenity value of water). Thus, the economic functions of water can basically be interpreted as the input function (e.g. in production and consumption) and the environmental and human services (e.g. providing regeneration of the natural resources and amenity values to human beings). This is consistent with the Dublin statement "water has an economic value in all its competing use and should be recognized as an economic good."

\footnotetext{
${ }^{1}$ Although derived from a central planner's problem, such a solution can be decentralized in the competitive market under the condition of convex production set, and continuous and concave utility function (Negishi 1960).
} 


\subsection{Rivalry/Non-rivalry and Excludability/Non-excludability}

Although water can be treated as an economic good, we have to understand its characteristics as water is part of the environmental resource systems. Due to the physical attributes, natural water often has specific characteristics related to the questions of whether it is rivalrous or nonrivalrous and whether users of water are excludable or non-excludable from its use. Non-rivalry refers to a situation in which the consumption of water by one individual does not reduce the availability of consumption by another. Non-excludability refers to the property that it is impossible to exclude people from consumption in a physical or legal sense. According to the different levels of involvement of non-rivalry and non-excludability, we may classify water as different types of good (or bad) in economic terms (Grafton et al. 2004):

- Water is a private good if it is both rivalrous and excludable;

- Water is a public good if it is both non-rivalrous, and non-excludable (or if exclusion costs are very high);

- Water is a common-pool resource (or open access resource) if it is rivalrous but nonexcludable (or if exclusion costs are very high);

- Water is a club good if it is non-rivalrous (at least to some extent), but excludable.

According to these classifications, we may find many examples for different types of water: a private good, a public good, a common-pool resource, or a club good. Firstly, typical water such as drinking water, agricultural and industrial water is a private good. This kind of water use is competing; water used for one purpose makes it unavailable for the other purposes. It is exclusive because one can exclude the others using water e.g. by piping the water to a specific location.

Secondly, flood-control projects are public goods because the benefits of projects can be enjoyed by anybody, whereas there is no opportunity in the market to charge for the extra costs (they are non-rivalrous and non-excludable). Water that is causing a flood is a public bad because nobody in the flooding area can be excluded and the fact that one person suffers from the troubles of flooding does not reduce the suffering of other people. A beautiful stream for recreation can be viewed as a public good because your enjoyment of the beauty of the stream does not reduce the possibility of other people enjoying it (non-rivalry) before congestion occurs, and the exclusion cost (such as building a wall or a fence around the stream) is too high.

Thirdly, groundwater (or water in a local lake) has been a common-pool resource in many regions of the world, because its use is rivalrous and the exclusion costs can be very high. On the one hand, groundwater is rivalrous, because your extraction will reduce the groundwater table (there is a limited volume of water under ground or a limited flow of groundwater) and the extraction possibility of other people will thus be reduced. On the other hand, the exclusion costs of using groundwater are very high. You can only stop people extracting water either by physical means such as setting monitoring equipment in many locations, or through laws, which incur high transaction costs or monitoring costs.

Finally, water for fishing can be a club good if fishermen have to pay for fishing (using of water for fishing), and if it is to some extent non-rivalrous because many people can go fishing at the same time and location, as long as no congestion occurs. In this case, the exclusion costs are low; simply introducing the fishing license or asking fishing men to pay the membership fee can exclude fishing for free.

\subsection{Causes of Water Scarcity and Water Pollution}

Water quantity is closely related to water scarcity. Water scarcity can be caused by the natural environment or by human activities. Earth water balance follows the hydrologic cycle. 
Precipitation, evaporation and runoff determine the water availability in the different seasons at various locations of the globe. In some areas water is abundant; while in other regions absolute water scarcity occurs. The patterns of precipitation and evaporation show huge variations over the seasons and over the years, which always has led to periods of drought and incidental floods in many areas.

Water quality issue is closely related to water pollution. Water pollution can be caused by human activities directly, but the environmental processes can also contribute to water pollution following the bio-physical laws. For example, climate change can worsen water quality due to a higher temperature. Managing water quality therefore needs understanding of the impacts on water quality of both the economic system and the environmental system.

\section{An Economic Framework for Water Quantity and Quality Management}

\subsection{Theoretical Background}

Economically, the efficiency of water allocation can be achieved through the first welfare theorem. The objective of the society according to this theorem is to maximise the social welfare subject to the economic constraints. Under very specific circumstances (e.g. absence of externalities and perfect competition), it can be shown that for given ownership of endowments, the resulting equilibrium allocation of the welfare program reflecting the social objective is Pareto-efficient ${ }^{2}$ (see Ginsburgh and Keyzer 2002).

However, the resulting allocation may be considered to be unacceptable from an equity perspective. A very careful design of the institutions is required to arrive at socially desirable outcomes that consider both allocative efficiency and distributional aspects. The potential compensation criterion is useful in separating efficiency and equity. This is addressed in the second welfare theorem. For the equity concern, the distributional goal can be achieved through transfers, in a setting which is also Pareto-efficient (Ginsburgh and Keyzer 2002). If the gains outweigh the losses, it would be possible for the gainers to compensate fully the losers with money transfers and still be better off with the policy.

In literature, environmental problems including amenity service of the environment have been represented in a welfare program (see e.g. Gerlagh and Keyzer 2003 and 2004; Zhu and van Ierland 2005). The welfare theorems indicate that Pareto-efficiency is achieved when the marginal benefits of using a good or service are equal to the marginal costs of supplying the good. In welfare economics, the shadow prices are determined by the marginal value of the resources (e.g. water).

Welfare economics found its application in water resource management already in early years (Krutilla 1981). Welfare economic theory provides a basis for economic valuations of water use because water is an input to economic activities. The value of water reflects its marginal contribution to the objective, i.e. by how much the value of the objective function increases if one more unit of water would be available. This is called the shadow price of water. The way of determining the value of water in a welfare program is called shadow pricing. Because of its economic value to the water users, shadow pricing of water can determine the willingness to pay of the users in the absence of markets. A shadow price, as

\footnotetext{
${ }^{2}$ A resource allocation is Pareto-efficient when it is impossible to reallocate resources to make an economic agent better off without making at least one economic agent worse off. In a welfare program, values of stock variables (shadow prices) are calculated according to capital theory, which can also be used for calculating the shadow price of accumulative pollution (see Keyzer 2000 for further information).
} 
the accounting price, therefore reflects the economic value of water. The advantage of using a welfare program is that the optimal solution can be decentralised in the competitive market (Ginsburgh and Keyzer 2002).

\subsection{Economic Models for Water}

In our economic analysis, we distinguish two characteristics of water in terms of its economic functions and special features, i.e. water quantity as a rivalrous good, and water quality considering pollution as a non-rivalrous good. They are represented in two types of models. The first type of model considers the input function of water in the production and consumption process and thus it is rivalrous. The second type considers both input and service (amenity) function, where water quality is influenced by the emissions from economic activities and has impacts on the utility of consumer utility and the production of producers. In this way, feedback effects of both water quantity and water quality are captured.

\subsubsection{Rivalrous Water as an Input to Economic Activities}

If water is a private good (i.e. rivalrous and excludable), the efficient allocation can be realised by a welfare program with a water market. If water is a common-pool resource, it is rivalrous but non-excludable. The non-excludability of water is caused by the fact that there are no clearly defined property rights. To achieve the optimal allocation of a common-pool resource, we can define a property right and establish a (pseudo-)market for it. Since the welfare optimum is equivalent to the equilibrium in a competitive market (i.e. utility maximization and profit maximization), an economic general equilibrium model can be represented as a welfare program. With clearly defined property rights and the establishment of a market for water, a welfare program can deal with different types of commodities distinguished by location and time dimension and can thus incorporate the spatial differentiation and seasonality of water. Particularly, in a welfare program we can determine the optimal allocation of a rivalrous good (e.g. private or common-pool water resource) and the shadow price of water.

Let us consider an economy with $r$ commodities indexed by $k=1,2, \ldots, r$. The commodity space is an $r$-dimensional space, denoted by $R^{r}$. The rivalrous water used as input for production or as final use for consumption in different seasons belong to this space. There are two types of agents who make decisions: producers (firms) and consumers. There are $n$ producers, indexed by $j=1,2, \ldots, n$. Each producer $j$ is endowed with a technology, represented by a set $Y_{j}$, which belongs to $R^{r}$. Let $y_{j}$ be the production plan with a vector of outputs and inputs (including water) of producer $j$, and the outputs of production carry a positive sign and inputs a negative sign. The feasible production plan is expressed as: $y_{j} \in Y_{j}$ . The producer chooses from the set of feasible production plans such that it maximises his/ her profit, defined as $p y_{j}$, where $p$ is the price vector. The problem of the producers can be described as: $\Pi_{j}(p)=\max _{y_{j}}\left\{p y_{j} \mid y_{j} \in Y_{j}\right\}$, where $\Pi_{j}(p)$ is the resulting maximal profit.

There are $m$ consumers, indexed by $i=1,2, \ldots, m$. Every consumer is endowed with commodity endowments including water resource $\omega_{i}$ for sale and sets his or her consumption plan such that his/her utility is maximized. The consumption of any commodity including water cannot be negative: $x \in R_{+}^{r}$. Each consumer is also faced with a budget constraint: $p x_{i} \leq h_{i}$, where $h_{i}$ is the income of consumer $i$. The income consists of two parts: the proceeds $p \omega_{i}$ of selling the endowment $\omega_{i}$ and the distributed profits $\sum_{j} \theta_{i j} \Pi_{j}(p)$, expressed 
as: $h_{i}=p \omega_{i}+\sum_{j} \theta_{i j} \Pi_{j}(p)$, where $\theta_{i j}$ is consumer $i$ 's non-negative share in firm $j$. All profits are distributed so that $\sum_{i} \theta_{i j}=1$ for producer $j$. The welfare program where water is a rivalrous good or common-pool resource reads:

$$
W(\alpha)=\quad \begin{gathered}
\max \sum_{i} \alpha_{i} u_{i}\left(x_{i}\right) \\
x_{i} \geq 0, \text { all } i, y_{j}, \text { all } j
\end{gathered}
$$

subject to

$$
\begin{gathered}
\sum_{i} x_{i} \leq \sum_{j} y_{j}+\sum_{i} \omega_{i} \quad(p), \\
y_{j} \in Y_{j}, \text { for all } j,
\end{gathered}
$$

where $x_{i}$ is the vector of consumption goods (including water) of consumer $i, y_{j}$ is the vector of outputs and inputs (including water) of producer $j, \omega$ is the vector of initial endowments (including water resource). Parameter in bracket $(p)$ gives the vector of shadow prices of the rivalrous goods (including water), $\alpha_{\mathrm{i}}$ is the welfare weight of consumer $i$ and is chosen such that his/her budget constraint holds,

$$
p x_{i}=p \omega_{i}+\sum_{j} \theta_{i j} \Pi_{j}(p) .
$$

By solving such a welfare program, the resulting solution shows the optimal allocation of goods including water with rivalry in production and/or consumption and their optimal shadow prices $(p)$.

For dealing with the competing use of water, the social objective is to achieve efficiency and equity of water allocation. The input function of water is valued by shadow prices in a market or pseudo-market in a welfare context. This welfare program sets up the mechanism of water quantity management based on economic efficiency. For the concern of equity, direct transfers can be made e.g. from the rich to the poor, which can be incorporated in the budget constraints. The framework proposed here is consistent with the hydro-economic modelling framework, because water regeneration (element of $\omega$ ) follows the hydrological process model.

\subsubsection{Non-rivalrous Water Quality as a Public Good}

Water pollution is to a large extent non-rivalrous because the negative impacts on one part of the environmental and economic system does not reduce the negative impacts on the other parts. For water quality management, we need to reduce its negative impacts on the environment and humans. Poor water quality has negative impacts on the economic activities of human beings because of the decreased capacity for life support and reduced water quantity caused by the regeneration process following hydrological processes. For example, lower water quality can have negative effects on crop growth or fish production.

Economically how can we solve the water quality problem (or improve the water quality) efficiently? Water quality has impacts on utility because of the health effects and amenity services, and it has impacts on production because of its input function. Therefore, it is necessary to include water quality, and its impacts on utility and the production function, in an economic model. Considering the non-rivalry of water quality, a welfare program can be used because it can accommodate different types of commodities including rivalrous and 
non-rivalrous goods (Ginsburgh and Keyzer 2002). Since water pollution is caused externally by emissions and water quality also depends on the water quantity available, water quality is actually a function of concentration of pollutants in a water body. Therefore, we can introduce a water quality function, which is a function of emissions and water quantity. Since there exists a threshold for concentration of pollutants in water, we can restrict the concentration to its threshold or safety standard. Because emissions result from economic activities, we can consider compensation by means of the 'polluters pay principle' and thus include 'externalities' in the welfare program. As such, the welfare program, which includes the water quality function, the non-rivalry of water quality, the impacts of water quality on utility and production, and the compensation for the caused pollution, can be stated as:

$$
\begin{gathered}
\max \sum_{i} \alpha_{i} u_{i}\left(x_{i}, g_{i}\right) \\
x_{i} \geq 0, g_{i} \geq 0 \text { all } i, y_{j} \text { all } j, y_{w}^{+} \geq 0,
\end{gathered}
$$

subject to

$$
\begin{array}{ll}
\sum_{i} x_{i} \leq \sum_{j} y_{j}+\sum_{i} \omega_{i} & (p), \\
& F_{j}\left(y_{j}, g_{j}, e_{j}\right) \leq 0, \\
g_{i}=y_{w}^{+} & \left(\phi_{i}\right), \text { for all } i, \\
g_{j}=y_{w}^{+} & \left(\phi_{j}\right), \text { for all } j, \\
e=\sum_{j} e_{j} \leq \bar{e} & (\psi), \\
F_{g}\left(y_{w}^{+}, e\right) \leq 0, &
\end{array}
$$

where $x_{i}$ is the vector of consumption goods (including water) of consumer $i, F_{j}$ is the transformation function of producer $j$ representing the production process according to a certain technology, which gives the relation between inputs including water and outputs $\left(y_{j}\right)$ and water quality $g_{j}$ as well as emissions $e_{j}$. Water quality $y_{w}^{+}$is "produced" according to a transformation function $F_{g}$, which is mainly determined by the total emissions $(e)$ and the hydrological process (which determines the available water quantity) as well as the biogeochemical circumstances. The non-rivalry of water quality is captured by $g_{i}=y_{w}^{+}$, which means every consumer $i$ faces the same water quality $y_{w}^{+}$. When water quality has an impact on production, the non-rivalry of water quality also applies to the producer, which means that producer $j$ faces the same water quality as well, i.e. $g_{j}=y_{w}^{+}$. Parameters $\phi_{i}$ and $\phi_{j}$ indicate the shadow prices of water quality, implying the willingness to pay of each consumer $i$ or the costs of each producer $j$ who is willing to pay for improving the water quality by one unit. Restricting the concentration of a pollutant in water to its threshold or safety standard is equivalent to limiting the total emissions to an emission bound $\bar{e}$, which can then determine the shadow price of emission $(\psi)$. This $\psi$ can be 
used as an emission tax or the compensation that the polluter has to pay. The welfare weight $\left(\alpha_{i}\right)$ is chosen such that his budget constraint holds,

$$
p x_{i}+\phi_{i} g_{i}=p \omega_{i}+\sum_{j} \theta_{i j} \Pi_{j}\left(p, \phi_{j}\right) .
$$

This welfare program can be applied for dealing with water allocation, the industrial pollution problem, trans-boundary water management, upstream and downstream interaction and pollution compensation and charges.

This framework is consistent with a hydro-economic model, as water quantity endowment is determined by the hydrological cycle. Moreover, it extends a hydro-economic model in that water quality is included and the process of water quality transformation follows a biophysical process model. In addition, feedbacks from water quality to the economic system (e.g. on the utility and production) are also explicitly considered. ${ }^{3}$

\section{An Illustration for Seasonal Water Management in a Numerical Example}

The economic principles discussed in Section 3 can be applied to real world cases. By specifying the welfare programs we may discuss how water systems in specific settings can be managed in an economically efficient way. Policy insights may be obtained from the results of well-designed integrated models. In this section we illustrate how to manage water by applying a welfare program and finding the policy implications of water management in the case of a local water system.

\subsection{Specification of the Welfare Program}

Consider an economy in which water use relies on a local water system (e.g. a river or a lake). In the economic system, the economic process follows given production technologies for production and given consumer preferences for consumption. In this system, there is water demand. Different users use water as a consumption good ${ }^{4}$ (e.g. drinking and bathing water for households) or an input e.g. irrigation for agricultural production, or cooling for industrial production. In the water system, water is supplied according to the hydrological cycle with precipitation, evaporation and runoff. Following this cycle, water quantity (i.e. availability) fluctuates over seasons. For simplicity, we distinguish a high and low season in a year according to the hydrological cycle. In the high season, there is higher precipitation, while in the low season, there is lower precipitation and possibly droughts. Water quality is determined, following the biophysical process, by the total emissions from production, which are released into water, and the water quantity. That is, water quality is a function of concentration of pollutants in water. The higher the emission level, the lower the water quality. The lower the water quantity, the lower the water quality, ceteris paribus.

A planner (water manager) wants to make the best use of the water system in order to achieve the sustainable economic development in the local economy. Particularly, the water manager aims to provide sufficient water for economic activity in the low season and sufficient water quality for sustaining the economy. The manager knows that he has two options for

\footnotetext{
${ }_{3}^{3}$ For simplicity, we have not explicitly included the time dimension in the theoretical framework. However, it can easily be modified to a dynamic setting if a time subscript is added to each variable and parameter in the model. In the specified model in Section 4 we have included two seasons.

${ }^{4}$ For simplicity we do not include a water utility for producing "tap" water in this model. Water is directly used by consumers and producers.
} 
managing water quantity. One is to reserve water in the high season for use in the low season. The other is to introduce different prices for water in different seasons because of the different demand. For managing water quality, he can charge an emission tax to those who release emissions into the water body, such that the pollutant concentration in water will be below the local threshold. Therefore the manager's problem is to determine the allocation of water over two seasons among different users, and the different prices in different seasons, as well as the emission charges. This problem can be solved by solving a specified welfare program.

For this problem, we need to specify the number of consumers and producers involved in this economy. We consider one aggregate representative consumer for households, and two production sectors that produce agricultural and industrial goods in this model economy. The utility of the consumer depends on the consumption of agricultural and industrial goods, water quantity and quality. Water is an input for both sectors and the two sectors also emit pollutants to the river at different levels. Agricultural production is influenced not only by the quantity of water, but also by the water quality. We specify the welfare program (2) for this problem, which is included in the Appendix.

\subsection{Solution to the Model and Policy Implications}

This is an optimization model with equality and inequality constraints. Obviously, it is very difficult to solve this model analytically, even though it is only a small-scale model with limited number of commodities, a simplified hydrological process for water quantity and a simplified biophysical process for water quality. Nevertheless, we can solve the model numerically, with the parameter values for the production and utility functions, the hydrological cycles and the biophysical processes from empirics, using optimization algorithms. We use the given parameters and exogenous variables ${ }^{5}$ in Table 1 to illustrate how to solve such a model. The software used is GAMS. ${ }^{6}$

We then numerically determine all the variables such as production and consumption of agricultural and industrial goods, water use of the consumer and producers, water reservation, and water quality. Shadow prices of all commodities are determined as the Lagrange multipliers during the optimization process. Since the model outcome is the solution to a planner's problem whose objective is to maximize the social welfare, it is efficient. Besides, this solution is decentralisable through markets because of the convexity of the used transformation functions (combination of Leontief, Cobb-Douglas and CES) and the concavity of the utility functions (Cobb-Douglas). Table 2 provides the results on allocation of water among different users over two seasons, emissions and factor uses. Table 3 shows their relative prices. ${ }^{7}$

Table 2 shows that $39 \%$ (235 out of $\left.600 \mathrm{~km}^{3}\right)$ of water in the high season will be reserved for use in the low season. The economy will allocate $10 \%$ of capital (i.e. 5 from $50 \mathrm{~K} €$ ) and $5 \%$ of labour ( 5 from $100 \mathrm{k}$-hours) for reserving water in order to meet the higher demand in the low season. The prices ${ }^{8}$ differ in the two seasons, namely $0.132 € / \mathrm{m}^{3}$ in the high season but $0.199 € / \mathrm{m}^{3}$ in the low season to achieve the best use of water. This is, water is about

\footnotetext{
${ }^{5}$ Many settings could be specified using this program. Our focus is on the illustration of how the model can be applied in a specific case.

${ }^{6}$ GAMS refers to General Algebraic Mathematical System. It is used for solving constrained optimization problems. See Rosenthal (2007) for details.

${ }^{7}$ For the focus on water pricing in different seasons, we assume the same production levels of industrial and agricultural goods in both seasons and thus the same emissions. Therefore, there is no seasonal differentiation for emission prices.

${ }^{8}$ Please note that in Table 3 relative prices are reported, which gives the total income (GDP) 408€. For interpretation of the results, we rescale prices based on the total income of $408 \mathrm{~K} €$.
} 
Table 1 Exogenous variables and given parameters

\begin{tabular}{llc}
\hline Variables and parameters & Units & Values \\
\hline Exogenous variables & & 50 \\
Capital $\bar{K}$ & $\mathrm{k} €$ & 100 \\
Labour $\bar{L}$ & $\mathrm{k}$-hours & 600 \\
Water volume in the high season $\omega_{H}$ & $\mathrm{~km}^{3}$ & 150 \\
Water volume in the low season $\omega_{L}$ & $\mathrm{~km}^{3}$ & 50 \\
Water for ecological requirement $\underline{W}$ & $\mathrm{~km}^{3}$ & 50 \\
Threshold concentration of pollutants $\bar{c}$ & $\mathrm{mg} / \mathrm{m}^{3}$ & \\
Given parameters & & 0.2 \\
Utility functions & & 0.25 \\
Water quantity share in high season $\rho_{H}$ & & 0.1 \\
Water quantity share in low season $\rho_{L}$ & & 0.4 \\
Water quantity share $\sigma$ & & \\
Consumption share of agricultural goods $\zeta$ & & 0.85 \\
Production functions & & 0.5 \\
Substitution elasticity for agricultural goods $\sigma_{1}$ & & 0.05 \\
Substitution elasticity for industrial goods $\sigma_{2}$ & & 25 \\
Cost share of water quality for agricultural goods $\delta$ & $100 \mathrm{~kg} / \mathrm{unit}$ & 10 \\
Emission coefficient for agricultural production $\mathrm{c}_{1}$ & $100 \mathrm{~kg} / \mathrm{unit}$ & \\
Emission coefficient for industrial production $\mathrm{c}_{2}$ & & $\mathrm{hours} / \mathrm{m}^{3}$ \\
Reserving water & & 0.02 \\
Capital parameter for reserving water $c_{k}$ & & 0.02 \\
Labour parameter for reserving water $c_{l}$ & &
\end{tabular}

$40 \%$ more expensive in the low season than in the high season (see Table 3 ). The households have the incentive to pay such a higher price because they value the water higher in their utility in the low season (for example, they prefer to use more water in the summer). The total consumption of water by production and consumption in the low season (e.g. dry summer) is $335 \mathrm{~km}^{3}$, while in the high season (e.g. winter) is $315 \mathrm{~km}^{3}$.

The water quality is determined by the concentration of pollutants in water relative to the local threshold (i.e. the ecological condition). An emission permit is set in order to meet the ecological bound. Since managers can expect different water amount in the low season from reserving or not reserving water, they should set different emission targets corresponding to the local threshold $\left(50 \mathrm{mg} / \mathrm{m}^{3}\right.$ in the numerical example). ${ }^{9}$ When no water is reserved (for example, if reservation technology is not available, or too expensive), the emission level reaches to $15,000 \mathrm{~kg}$ (for which the concentration reaches its threshold) such that the water quality in the low season reaches its lowest level (100). When $235 \mathrm{~km}^{3}$ water is reserved, the concentration in the low season decreases and water quality improves. If we restrict the concentration below the same threshold, more emissions are allowed and the emission level reaches $21,800 \mathrm{~kg}$. The agricultural producer emits $5,400 \mathrm{~kg}$ and industrial producer $16,400 \mathrm{~kg}$. If an emission tax should be levied, a producer would pay $940 € /$ tonne.

In order to obtain the insights of seasonal water pricing and water allocation by water reservation as illustrated in this example, we compare the consumer welfare level with that in

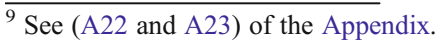


Table 2 Optimal allocation of water quantity, quality, emissions and production factors

\begin{tabular}{|c|c|c|c|}
\hline & High season & Low season & Yearly \\
\hline \multicolumn{4}{|l|}{ Water quantity $\left(\mathrm{km}^{3}\right)$} \\
\hline Agricultural producer $W_{1}$ & 11 & 11 & 22 \\
\hline Industrial producer $W_{2}$ & 41 & 41 & 82 \\
\hline Consumer $x_{w H}, x_{w L}$ & 263 & 283 & 546 \\
\hline Total water use & 315 & 335 & 650 \\
\hline Ecological requirement $\underline{W}$ & 50 & 50 & 100 \\
\hline Reserved water $W_{R}$ & 235 & -235 & 0 \\
\hline Endowment $\omega_{H}$ and $\omega_{L}$ & 600 & 150 & 750 \\
\hline Water quality $g$ & 164 & 121 & \\
\hline \multicolumn{4}{|l|}{ Emissions (100kg) } \\
\hline Agricultural producer $e_{1}$ & 27 & 27 & 54 \\
\hline Industrial producer $e_{2}$ & 82 & 82 & 164 \\
\hline Total emissions e & 109 & 109 & 218 \\
\hline \multicolumn{4}{|l|}{ Factors } \\
\hline \multicolumn{4}{|l|}{ Capital (k€) } \\
\hline Agricultural producer $K_{1}$ & 14 & 14 & 28 \\
\hline Industrial producer $K_{2}$ & 8.5 & 8.5 & 17 \\
\hline Reserving water $K_{R}$ & 5 & & 5 \\
\hline Total capital use & 27.5 & 22.5 & 50 \\
\hline \multicolumn{4}{|l|}{ Labour (k- hours) } \\
\hline Agricultural producer $L_{1}$ & 33 & 33 & 66 \\
\hline Industrial producer $L_{2}$ & 14.5 & 14.5 & 29 \\
\hline Reserving water $L_{R}$ & 5 & & 5 \\
\hline Total labour use & 52.5 & 47.5 & 100 \\
\hline
\end{tabular}

Number in Italics are the direct values of the variables in the first column.

the no-water-reservation case. The same model is applied to the latter case. The comparison shows that if we invest some capital and labour for water reservation and introduce the lowhigh season prices for water use, the total welfare of the consumer is increased from 29 to 35. This result indicates that proper water management can achieve a higher welfare level, and low-high season water pricing makes water use more efficiently.

Table 3 Prices for water quantity, water quality, emissions, production factors, agricultural and industrial goods

\begin{tabular}{lccc}
\hline & High season & Low season & Low-high ratio \\
\hline Water quantity price & 0.131 & 0.185 & 1.41 \\
Water quality price & 0.132 & 0.199 & 1.51 \\
Emissions price & 0.094 & 0.094 & 1.00 \\
Capital price & 2.774 & 2.774 & 1.00 \\
Labour price & 1.000 & 1.000 & 1.00 \\
Agricultural goods price & 74.133 & 74.133 & 1.00 \\
Industrial goods price & 6.464 & 6.464 & 1.00 \\
\hline
\end{tabular}


Of course, how much water to reserve and how to differentiate prices for seasonal water depends crucially on the reservation technology and other parameters in the model. In our example, we have so far set the reservation cost parameters to $0.02 € / \mathrm{m}^{3}$ for capital and $0.02 \mathrm{~h} /$ $\mathrm{m}^{3}$ for labour. If we use a wide range for the values of the reservation cost parameters in the model, we can obtain a clear picture of how reservation technology and its related costs can influence our decisions. Figure 1 shows the relation between the values of reservation cost parameters and the quantities of reserved water and the low-high price ratios. As the value of parameters for reserving water goes up, less water will be reserved and higher prices in the low season should be charged relative to the high season. This example clearly shows the two possibilities for policy instruments of managing water. On one hand, we can use reservation technology to allocate water. In this sense, technological progress or the setting of standards (corresponding to low reservation cost parameter values) can stimulate water conservation (Olmstead 2010), because more water can be reserved with better technology. On the other hand, we can rely on economic instruments (in this example, to introduce a higher price in the low season) to achieve the efficient use of water if we have seasonal water supply and demand. When there is no reservation possibility (e.g. if it is too expensive), we can only rely on pricing. Then the price ratio for low-high season becomes 7.05. This also indicates although both water reservation technology and water pricing can be used, we may choose one or both instruments depending on the reservation technology. If the reservation technology is expensive, we may use only differential prices, while when reservation technology becomes cheaper we may reserve more water, thus less differentiation of prices is required.

We have shown in this example that we can achieve an efficient allocation of water and simultaneously a desirable level of water quality through reservation and pricing. The important policy implication is how to achieve the decentralisation of the efficient allocation and implementation of water pricing. As long as relevant institutions are provided (property rights of water are defined, water markets are established and every water user agrees to pay for the use of water), an efficient allocation can be achieved in a decentralised manner. Therefore, the policy implication is to ensure such an institutional arrangement.

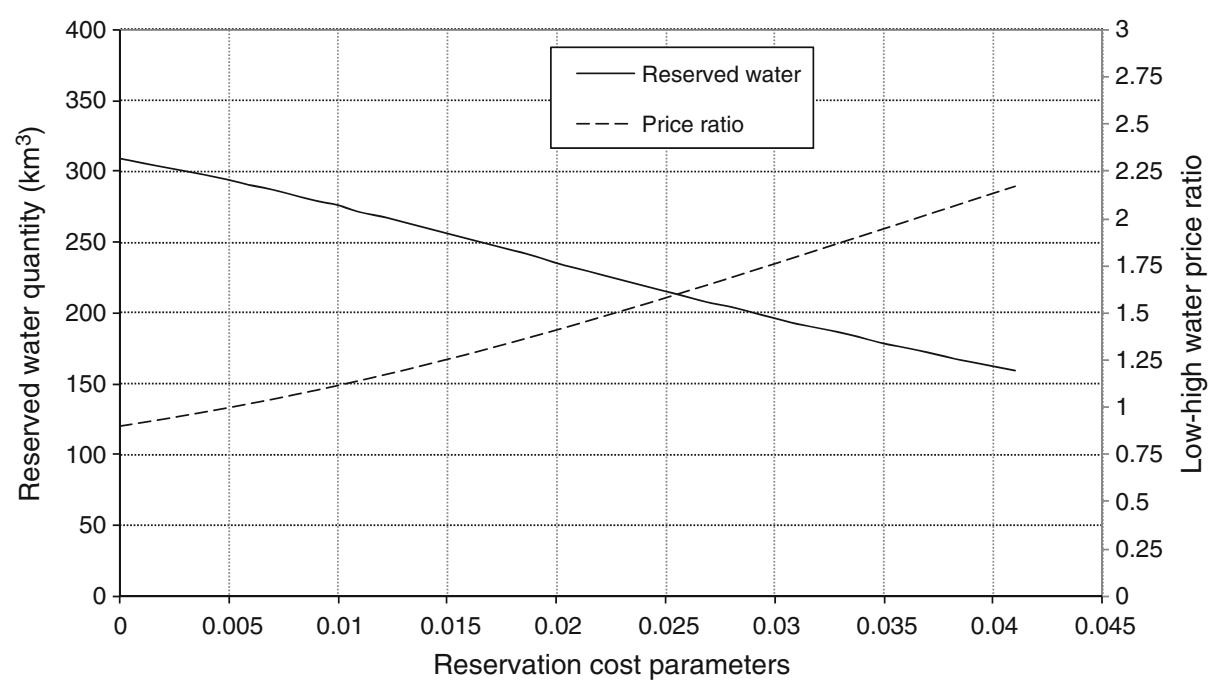

Fig. 1 Relation between reservation cost parameters and reserved water quantity and price ratio of low-high season 


\section{Conclusions}

The objective of this study is to present an integrated modelling framework that can deal with efficient allocation and management of water quantity and quality. We started with a discussion on the special features of water regarding the rivalry/non-rivalry and excludability/non-excludability of water resources. Next, the economic mechanisms were explored in welfare programs of managing the water quantity as a rivalrous good (i.e. a private good or a common-pool resource) and water quality as a non-rivalrous good (i.e. a public good).

This paper elaborated on the economic instruments of dealing with water quantity and quality issues, including to what extent water can be reserved and how much pollution compensation (or tax) should be paid. We illustrated how to manage seasonal water for a local economy using the theoretical framework in a numerical example and discussed the policy implications. By solving the model in an a numerical example, it was shown how much water could be reserved in the high season for the use in the low season, given reservation technology, when there were seasonal differences in water availability. Differentiated prices were introduced based on the concept of shadow pricing because of different demands in different seasons. Price differentiation in different seasons can achieve a higher total welfare, thus it is a Paretoimprovement. Moreover, the level of the emission tax could be charged to the polluter for a certain water quality target determined by the local threshold.

In this study we have discussed two policy instruments, i.e. reservation technology and pricing. The policy implications are as follows. First, quantity management is closely related to water scarcity. It is worthwhile to invest on the reservation technology to decrease the factor (e.g. capital and labour) input in reserving water, because the amount of water reserved is limited due to limited availability of production factors. Only if feasible reserving technology is available, is there a possibility to reserve water, for example, in the high season for the high demand in the low season.

Second, it is important to use the pricing instrument and institutional arrangement for water quantity management. Management of water quantity requires us to understand the causes of the scarcity and the involved properties such as rivalry. Scarcity can be linked to the rivalry characteristic of water, because rivalry causes the competing use of water. Particularly, for rivalrous water (i.e. a private good and a common-pool resource) such as drinking water, agricultural and industrial water, the existing markets can be used to achieve economic efficiency. For example, households pay the water bill to the water company for the consumption of the drinking water in a price which in most cases is supposed to reflect the market price. In the case of different seasonal water availability and demand, it is recommended to introduce differentiate prices, for example, using higher price in the low season than in the high season as shown in our numerical example. But if water is un-priced or underpriced, for instance, in agriculture due to undefined property rights (e.g. commonpool water resources such as groundwater), it is useful to define the water rights first and then price water properly according to its scarcity or marginal value (i.e. shadow pricing). If water is a non-rivalrous good (i.e. a public good such as a beautiful water resort), the policy requirement is to exclude the "free-riders" by institutional arrangements (e.g. by law) or by physical exclusion or simply decide to provide the non-rivalrous good by a public authority for the sake of the public. In the latter case the costs need to be covered by tax payments.

Third, as far as water quality is concerned, it is important to improve water quality because of its impact on economic activities and environmental services. The causes of water pollution are mainly the emissions from economic activities. From the perspective of policy making, it is thus important to implement proper measures, particularly economic instruments to reduce emissions, based on principles such as the 'polluters pay principle'. 
Institutional arrangement such as levying pollution taxes may be needed for such policies. Similarly, the pollution tax can be determined by the marginal value of the emission permit, based on shadow pricing in a welfare program. Besides, a decrease in water quality also contributes to the reduction of water quantity because less clean water is available in the case of lower water quality. In this case, we may consider, for example, the reuse of 'waste' water.

The exercise we conducted in this paper is only an attempt to tackle the water management problem by consistent economic modelling of the economic aspects of water in its various uses. Much more further work is needed. As competing demands for water exceed supply in more and more regions of the world, economics clearly has much to contribute to the design of policy. An important task for modelling water resource problems is to improve the representation of the hydrological cycle of water quantity and the biophysical process of water quality in economic models. Spatial and temporal dimensions appear to be particularly important for water demand. As Harou et al. (2009) point out, the variation of water values in time and space will increasingly motivate efforts to address water scarcity and reduce water conflicts. In the case of environmental change, the interaction between the economic and the environmental system and the related environmental processes deserve more attention. In the perspective of climate change, economic modelling should consider the impacts of climate change on the hydrological cycle, which affects the quantitative and qualitative status of the water resources. Feedbacks and interactions between economic and water system should be carefully incorporated in the model, which helps identify the 'best' policy options.

Acknowledgments The authors would like to acknowledge the financial support from the EU NeWater project under contract no. No.5111179. We would like to thank the two reviewers for the comments for improving the paper. We appreciate the comments received from the participants in the Fourth World Congress of Environmental and Resource Economists (WCERE) in 2010, Montreal, Canada. We also appreciate the comments from Erik Ansink on an earlier version of this paper and the language improvement made by Adam Walker. The remaining errors are ours.

Open Access This article is distributed under the terms of the Creative Commons Attribution License which permits any use, distribution, and reproduction in any medium, provided the original author(s) and the source are credited.

\section{Appendix Model specification}

\section{Utility and Objective Function}

Since there is different demand by the households in different seasons, there are different parameter values in utility functions in different seasons. For example, water is demanded more in the low season (e.g. watering gardens and bathing due to hot weather) than in the high season, so there is a higher expenditure share. The utility function for the high and low season can be written as:

$$
\begin{aligned}
& u_{H}=x_{w H} \rho_{H}\left\{g^{\sigma}\left[x_{1}^{\zeta} x_{2}{ }^{1-\zeta}\right]^{1-\sigma}\right\}^{1-\rho_{H}} \\
& u_{L}=x_{w L}^{\rho_{L}}\left\{g^{\sigma}\left[x_{1}^{\zeta} x_{2}{ }^{1-\zeta}\right]^{1-\sigma}\right\}^{1-\rho_{L}}
\end{aligned}
$$

where $\rho_{H}, \rho_{L}$ is the expenditure share of water in the high and low season respectively, but $\rho_{H} \leq \rho_{L}$ because the consumer is willing to spend more on water in the low season than in the high season. 
The objective of the water manager is to maximize the sum of the consumer utility in the high and low season, by allocating water in the high and low season and introducing different prices, subject to the economic constraint (e.g. limited production factors, given production technology) and ecological constraint (e.g. water availability), which leads to the highest welfare in the year. That is:

$$
\max \left(u_{L}+u_{H}\right)
$$

subject to the transformation functions and balance equations of commodities such that the budget constraint of the consumer is fulfilled.

Transformation Functions of Agricultural Good, Industrial Good, Water Quantity and Quality

Transformation function of agricultural and industrial goods can be written in the Leontief form due to the non-substitutability between water input and factor inputs.

$$
\begin{gathered}
F_{1}=y_{1}-\min \left\{W_{1}, \operatorname{Ag}^{\delta}\left[\operatorname{CES}\left(K_{1}, L_{1}, \sigma_{1}\right)\right]^{1-\delta}\right\} \leq 0, \\
F_{2}=y_{2}-\min \left\{W_{2}, \operatorname{CES}\left(K_{2}, L_{2}, \sigma_{2}\right)\right\} \leq 0,
\end{gathered}
$$

where $y_{1}, y_{2}$ are the production quantity for agricultural and industrial goods respectively, $K$, $L$ are capital and labour input in production, $\sigma$ is the substitution parameter between capital and labour, and $W$ is the water input. Subscripts 1 and 2 refer to agricultural and industrial production. It is assumed that water quality $g$ influences the agricultural production due to irrigation but not the industrial production because water is used for cleaning purpose only, and parameter $\delta$ is the Cobb-Douglas exponent for water quality.

As we have mentioned, water supply (i.e. water endowment) in the river in the high and low season follows the hydrological cycles of precipitation, evaporation and runoff, i.e.:

$$
\begin{gathered}
\omega_{H}=P R_{H}-E V_{H}-R F_{H} \\
\omega_{L}=P R_{L}-E V_{L}-R F_{L},
\end{gathered}
$$

where $\omega$ is the water endowment, $P R, E V$ and $R F$ are the precipitation, evaporation and runoff in the local river, with subscripts $H$ and $L$ for the high and low season respectively. We also have the following relations: $P R_{H}>P R_{L}, E V_{H}>E V_{L}$ and $R F_{H}>R F_{L}$. That is, we have: $\omega_{H}>\omega_{L}$. For simplicity, in the numerical example we assume $\omega_{H}=600$, and $\omega_{L}=150$.

Transformation function of water quality follows the biophysical process, and we assume that water quality is determined by the emissions of pollutants and water quantity. We use the following relationship:

$$
\begin{gathered}
F_{g H}=y_{w H}^{+}-100\left(2-\frac{e_{H} / \omega_{H}}{\bar{c}}\right) \leq 0, \\
F_{g L}=y_{w L}^{+}-100\left(2-\frac{e_{L} / \omega_{L}}{\bar{c}}\right) \leq 0,
\end{gathered}
$$

where $y_{w}^{+}$is the water quality indicator, $e$ is the emissions from the economic system, e/ $\omega$ is the concentration of pollutants with subscripts $H$ and $L$ for the high and low season 
respectively and $\bar{c}$ is the threshold of water contamination reflecting the ecological limit, which depends on the local circumstances. For example, the water concentration of nitrate for EU water-bodies is, for safety reasons, restricted to $50 \mathrm{mg} / \mathrm{L}$. Seasonal water quality will be further specified later when emissions are presented.

Balance Functions of Commodities (Agricultural and Industrial Good, Water Quantity, Production Factors, Water Quality and Emissions)

Agricultural and industrial goods are subject to:

$$
x_{j}-y_{j} \leq 0, \quad\left(p_{j}\right),
$$

where $j=1$ and 2 refer to the agricultural and industrial good respectively, with $x$ for the consumption, $y$ for the production quantity and $\mathrm{p}$ for the shadow prices.

For representing the balance function of water quantity, we have defined the water supply (A6 and A7). We now determine the water demand, and then the balance equation. Water demand include the water quantity used by the consumer and the producers. We consider that only the consumer uses different amount of water in the different seasons (for example, a higher preference for frequent bathing and gardening in the summer) but there are no seasonal differences for the producers (for continuous production with the same production technology in different seasons) in this model. Thus the total levels of water consumption (demand) in the high and low season are respectively:

$$
\begin{aligned}
& W_{H}=\frac{1}{2}\left(W_{1}+W_{2}\right)+x_{w H} \\
& W_{L}=\frac{1}{2}\left(W_{1}+W_{2}\right)+x_{w L},
\end{aligned}
$$

where $W_{1}$ and $W_{2}$ are the water quantity used for agricultural and industrial production in the whole year, $x_{w H}$ and $x_{w L}$ are the water quantity used by the consumer in the high and low season.

The other use of water is to ensure that there is sufficient water in the river in both seasons (e.g. for fish) as the ecological requirement, and probably reserve a certain amount of water in the high season for the later use in the low season. All the water use should not exceed the water supply, i.e. the water balance should be fulfilled:

$$
\begin{aligned}
& W_{H}+\underline{W}+W_{R} \leq \omega_{H} \quad\left(p_{w H}\right) \\
& W_{L}+\underline{W} \leq \omega_{L}+W_{R} \quad\left(p_{w L}\right),
\end{aligned}
$$

where $\underline{W}$ is the minimum amount of water in the river, which is determined by the ecological requirement, and $W_{R}$ is the amount of water that can be stored in a reservoir (i.e. water reservation) in the high season with $W_{R} \geq 0$, which can be used in the low season. Parameters in brackets are the shadow prices of water in the high and low season.

The reservation of water uses capital and labour (i.e. there is a water reserving sector to produce reserved water using the production function $f(K, L))$. Assuming that reserving one unit of water needs $c_{k}$ of capital and $c_{l}$ of labour, the labour and capital used for water reservation $W_{R}$ is: $K_{R}=c_{k} W_{R}$, and $L_{R}=c_{l} W_{R}$. Labour and capital used in production of 
agricultural and industrial goods and in reserving water should not exceed the initial endowments. Their balance equations are:

$$
\begin{gathered}
L_{1}+L_{2}+L_{R} \leq \bar{L} \quad(w) \\
K_{1}+K_{2}+K_{R} \leq \bar{K} \quad(r),
\end{gathered}
$$

where $L_{1}, L_{2}$ is the labour input and $K_{1}, K_{2}$ is the capital input for agricultural and industrial production, $\bar{L}, \bar{K}$ is the labour and capital endowment, $w$ is the wage for labour and $r$ is the rent for capital.

Due to the different seasonal water quantities and the possible reserved water which is used in the low season, we expect different quality in the two seasons as well. (A8) and (A9) can thus be expressed as:

$$
\begin{gathered}
y_{w H}^{+} \leq 100\left(2-\frac{c_{H}}{\bar{c}}\right), \\
y_{w L}^{+} \leq 100\left(2-\frac{c_{L}}{\bar{c}}\right),
\end{gathered}
$$

where $c_{H}$ and $c_{L}$ are the concentrations of pollutants in water in the high and low season respectively. They are calculated as:

$$
\begin{gathered}
c_{H}=e_{H} / \omega_{H}, \\
c_{L}=\frac{\frac{e_{H}}{\omega_{H}} W_{R}+e_{L}}{\left(\omega_{L}+W_{R}\right)},
\end{gathered}
$$

where $e_{H}$ and $e_{L}$ are the emission pollutants in the high and low season. Yearly emissions of pollutants from the agricultural and industrial production are $e_{1}, e_{2}$, which are calculated by the emission coefficients of the producers, i.e. $e_{1}=c_{1} y_{1}$ and $e_{2}=c_{2} y_{2}$. The total yearly emissions to water are thus: $e=e_{1}+e_{2}$. Since emissions are the flows of pollutants to the water body, we assume that pollutants enter to water at the same rates in the high and low season. Thus,

$$
e_{H}=e_{L}=\frac{1}{2} e
$$

The emission level should be constrained by the threshold of the water contamination, which ensures a certain level of water quality. That is, the concentrations in both seasons are limited to the threshold:

$$
\begin{gathered}
c_{H} \leq \bar{c} \quad\left(\zeta_{H}\right), \\
c_{L} \leq \bar{c} \quad\left(\zeta_{L}\right) .
\end{gathered}
$$

where $\zeta_{H}$ and $\zeta_{L}$ are the shadow prices of pollution concentration in water in the high and low season, implying the marginal costs of reducing the concentrations of pollutants. 
Emission bound $\bar{e}$ is the lowest emission level fulfilling the two conditions (A22 and A23). Emissions should be priced according to:

$$
e \leq \bar{e} \quad(\psi) .
$$

A producer should pay for his pollution or buy a permit for releasing pollutants. Parameter $\psi$ in (A24) is the shadow price of emission, or the pollution tax.

Water quality is non-rivalrous for the consumer and the agricultural producer, so an equality is used for the balance equation:

$$
\begin{array}{ll}
g_{H}=y_{w H}^{+} & \left(\phi_{H}\right) \\
g_{L}=y_{w L}^{+} & \left(\phi_{L}\right)
\end{array}
$$

where parameter $\phi$ is the price of water quality.

In this model, parameters in brackets of all the commodity balances (A10, A13, A14, A15, A16, A22, A23, A24, A25 and A26) are the Lagrange multipliers, which are the shadow prices of the corresponding commodities. They can be determined in the numerical solution. The price of water in the high and low season is determined by $p_{w H}$ and $p_{w L}$, reflecting the different values of water in the two seasons. The shadow price of water quality $(\phi)$ reflects the willingness to pay of the consumer or the producer if water quality is improved by one unit. It is also easy to see that the producer has to pay the emission charge $\psi$ for per unit of emissions.

Now everything is priced, so the consumer has to pay for the consumption of agricultural and industrial goods, water quantity and the enjoyment of water quality. Thus the following budget constraints for the consumer in both seasons can be formulated:

$$
\begin{gathered}
\left(p_{1} x_{1}+p_{2} x_{2}\right) / 2+p_{w H} x_{w H}+\phi_{H} g_{H} \leq I_{H} \\
\left(p_{1} x_{1}+p_{2} x_{2}\right) / 2+p_{w L} x_{w L}+\phi_{L} g_{L} \leq I_{L}
\end{gathered}
$$

where $I_{H}$ and $I_{L}$ are the consumer budget in the high and low season when water is priced.

Using the standard economic mechanism, the consumer owns all the endowments so that all the revenues are attributed to the consumer. The consumer will receive the remuneration of labour and capital, the water revenue, the remuneration of water quality as well as the revenue of emission taxes paid by the producers. The following two formula give the income in the high and low season respectively.

$$
\begin{gathered}
I_{H}=(r \bar{K}+w \bar{L}) / 2+p_{w H}\left(\omega_{H}-W_{R}-\underline{W}\right)+\phi_{H} y_{w H}^{+}+\psi e / 2, \\
I_{L}=(r \bar{K}+w \bar{L}) / 2+p_{w L}\left(\omega_{L}+W_{R}-\underline{W}\right)+\phi_{L} y_{w L}^{+}+\psi e / 2 .
\end{gathered}
$$

This completes the whole model, which consists of one objective function (A3) and 27 constraints (A1-A30 excluding A3, A8 and A9). 


\section{References}

Albersen PJ, Houba HED, Keyzer MA (2003) Pricing a raindrop in a process-based model: general methodology and a case study of the Upper-Zambezi. Phys Chem Earth 28:183-192. doi:10.1016/ S1474-7065(03)00024-X

Ansink E, Ruijs A (2008) Climate change and the stability of water allocation agreements. Environ Resour Econ 41:249-266

Babel MS, Das Gupta A, Nayak DK (2005) A model for optimal allocation of water to competing demands. Water Resour Manag 19:693-712

Batten DF (2007) Can economists value water's multiple benefits? Water Pol 9:345-362

Braden JB, van Ierland EC (1999) Balancing: the economic approaches to sustainable water management. Water Sci Technol 39:17-23

Briscoe J (2005) Water as an economic good. In: Brouwer R, Pearce D (eds) Cost-benefit analysis and water resources management. Edward Elgar, Cheltenham and Northampton, pp 46-70

Brouwer R, Hofkes M (2008) Integrated hydro-economic modelling: approaches, key issues and future research directions. Ecol Econ 66:16-22

Cai X, Mckinney DC, Lasdon LS (2003) Integrated hydrologic-agronomic-economic model for river basin management. J Water Resour Plann Manag 129:4-17

Chakravorty UE, Hochman E, Zilberman D (1995) A spatial model of optimal water conveyance. J Environ Econ Manag 29:25-41

Dinar A, Letey J (1991) Agricultural water marketing, allocative efficiency, and drainage reduction. J Environ Econ Manag 20:210-223

Fisher FM (2008) Water value, water management and water conflict: a systematic approach. In: Wiegandt E (ed) Mountains: Sources of water, sources of knowledge, Springer, pp 123-148.

Gerlagh R, Keyzer MA (2003) Efficiency of conservationist measures: an optimist viewpoint. J Environ Econ Manag 46:310-333

Gerlagh R, Keyzer MA (2004) Path-dependence in a Ramsey model with resource amenities and limited regeneration. J Econ Dyn Control 28:1159-1184

Ginsburgh V, Keyzer MA (2002) The structure of applied general equilibrium models. The MIT Press, Cambridge, Massachusetts and London, England

Grafton RQ, Adamowicz W, Dupont D, Nelson H, Hill RJ, Renzetti S (2004) The economics of the environment and natural resources. Blackwell Publishing Ltd, Malden, USA, Oxford, UK and Victoria, Australia

GWP-TAC (Global Water Partnership -Technical Advisory Committee) (2000) Integrated water resources management. TAC Background papers No.4, Stockholm, Sweden.

Harou JJ, Pulido-Velazquez M, Rosenberg DE, Medelin-Azuara J, Lund JR, Howitt RE (2009) Hydroeconomic models: concepts, design, applications and future prospects. J Hydrol 375:627-643

Heinz I, Pulido-Velazquez M, Lund JR, Andreu J (2007) Hydro-economic modelling in river basin management: implications and applications for the European water framework directive. Water Resour Manag 21:1103-1125

Hellegers P, Zilberman D, Steduto P, McCornick P (2008) Interactions between water, energy, food and environment: evolving perspectives and policy issues. Water Pol 10(Supplement 1):1-10

Kemper K (1996) The cost of free water: water resources allocation and use in the Curu Vally, Ceara, Northeast Brazil. PhD thesis, Linkoping University

Keyzer MA (2000) Pricing a raindrop: the value of stocks and flows in process-based models with renewable resources. Working paper WP-00-05, Centre for World Food Studies, Vrije Universiteit, Amsterdam.

Koch H, Grünewald U (2009) A comparison of modelling systems for the development and revision of water resources management plans. Water Resour Manag 23:1403-1422

Krutilla JV (1981) Reflections of an applied welfare economist. J Environ Econ Manag 8:1-10

Loehman E, Dinar A (1994) Cooperative solution of local externality problems: a case of mechanism design applied to irrigation. J Environ Econ Manag 26:235-256

Negishi T (1960) Welfare economics and existence of an equilibrium for a competitive economy. Metroeconomica 12:92-97

Olmstead SM (2010) The economics of managing scarce water resources. Rev Environ Econ Pol 4:179-198

Pahl-Wostl C (2004) The implications of complexity for integrated resources management. Keynote paper in Phal-Wostl C, Schimidt S, Jakeman T (eds) iEMSs 2004 International congress on complexity and integrated resources management. Osnabrück, Germany, June 2004.

Prodanovic P, Simonovic SP (2010) An operational model for support of integrated watershed management. Water Resour Manag 24:1161-1194 
Qureshi ME, Qureshi SE, Bajracharya K, Kirby M (2008) Integrated biophysical and economic modelling framework to assess impacts of alternative groundwater management options. Water Resour Manag 22:321-341

Rosegrant MW, Ringler C, McKinney DC, Cai X, Keller A, Donoso G (2000) Integrated economichydrologic water modeling at the basin scale: the Maipo river basin. Agric Econ 24:33-46. doi:10.1111/j.1574-0862.2000.tb00091.x

Rosenthal R (2007) GAMS - a user's guide. GAMS Development Corporation, Washington DC, USA

Shaw WD (2005) Water resource economics and policy: an introduction. Edward Elgar Publishing Limited, Cheltenham

Viscusi WK, Huber J, Bell J (2008) The economic value of water quality. Environ Resour Econ 41:169-187

Yaron D (1979) A model for the analysis of seasonal aspects of water quality control. J Environ Econ Manag 6:140-151

Young RA (2005) Determining the economic value of water - concepts and methods. Resources for the Future, Washington DC, USA

Zhu X, van Ierland EC (2005) A model for consumers' preferences for Novel Protein Foods and environmental quality. Econ Model 22:720-744 